THURSDAY, MARCH 2, 1905.

\section{A TEXT-BOOK OF ELECTROMAGNETISM.}

Elements of Electromagnetic Theory. By S. J Barnett, Ph.D. Pp. 480. (New York: The Macmillan Company; London: Macmillan and Co., Ltd., I903.) Price I2s. 6d, net.

MODERN electromagnetic theory is so full of $\mathrm{M}$ interest, and yet at the same time so full of difficulties, that every fresh attempt to present an elementary account of it in a systematic and connected form is sure to attract the attention of students who are endeavouring to gain a grasp of the fundamental principles of the subject. Such students are always looking out for a "good text. book," hoping that this book, when found, will be better adapted to their needs than those they already possess. Their desire for something better probably arises, in part, from the difficulty of the subject, and the large number of new ideas which it presents to their minds. It is perhaps too much to expect that a student should be able to gain from any single book really vivid physical conceptions of electric and magnetic phenomena and principles, for perhaps, after all, these can only gradually grow in the mind. The author of the treatise under review has, it is clear, made a serious attempt to supply the student's want, so far, at least, as the more formal theory is concerned.

The book is meant to give an introduction to the subject, and thus the author does well to keep the analytical processes within the limits which are suitable for students whose mathematical attainments do not go beyond some knowledge of the differential and integral calculus and of simple differential equations.

In the first part of the book, general electrostatic theory is treated in a fairly complete way, many problems being solved. The chapters on the conduction current, on electrolysis and on thermal and voltaic E.M.F.'s, which then follow, will be found useful. The author next introduces magnetism, the magnetic action of currents, electromagnetic induction and the magnetic effects of moving charges, and concludes with a chapter on the transference of electromagnetic energy and on electromagnetic waves.

Throughout the book the system of rational units originated by $\mathrm{Mr}$. Oliver Heaviside is employed. On this system, if two unit charges are placed at unit distance apart in a vacuum, each exerts a force of $1 / 4^{\pi}$ dynes upon the other. The adoption of this system banishes the great $4^{\pi}$ from many important formulæ; for instance, on the rational system, the magnetomotive force in any circuit is numerically equal to the total current linked with the circuit, and the energy per unit volume in an electrostatic field is $\frac{1}{2} c \mathrm{E}^{2}$, where $\mathrm{E}$ is the electric force and $c$ the specific inductive capacity. But though the $4^{\pi}$ is driven from some formulæ it finds a refuge in others, with the result that every one of the rational units corresponding to the practical units, i.e, to the
Coulomb, Volt, Farad, Ampere, Ohm, Gauss, Maxwell and Henry, differs from the practical unit by some power of $4 \pi$. Yet the rational system is doubtless an advantage from the point of view of pure theory, and would probably have been adopted in practice if only there had been someone to suggest it in the early days of the science. The student must remember that he is using the rational system when he compares the formulæ in this treatise with those in most other text-books.

The magnetic properties of currents are deduced from Ampère's result that the mechanical action experienced by a circuit carrying a current $I$ is the same as it would experience if each element of length $d \mathrm{~L}$ were acted on by a force $\mathrm{IB} \sin \theta . d \mathrm{~L}$, where $\mathrm{B}$ is the magnetic induction and $\theta$ is the angle between $d \mathrm{~L}$ and $\mathrm{B}$; the direction of the force is at right angles to both $d \mathrm{~L}$ and $\mathrm{B}$. In this way the idea of the equivalent magnetic shell is avoided, and, in fact, we have found no mention of a magnetic shell in the book. Yet the ideas which group themselves round a magnetic shell and the solid angle subtended by it are of real assistance, and are not easily replaced.

The book, for the most part, goes over well worn ground, and thus the reviewer's attention is naturally directed more to the treatment of the various propositions than to the propositions themselves. The treatment is generally fresh and vigorous, but in a few instances is hardly satisfactory. Taking the electrostatic field due to a point-charge, the author considers the equilibrium of a portion of the field bounded by an elementary circular cone and two concentric spheres, and shows that the tension along the lines of force requires a pressure of equal amount at right angles to them. The result is extended to the general case by the remark that " since the field within the element of volume is uniform when the element is made indefinitely small, and since this is true of any electric field, the result just obtained for a radial field holds universally."

The attempt to establish a general result by the consideration of a single special case is seldom satisfactory. In the present instance the student would not fail to notice that the method which succeeds for the non-uniform field within the conical element will not apply if the tube of force is a circular cylinder so that the field within the element is really uniform.

In chapter xiii. "the coefficient of self induction (L) of a coil or circuit is defined to be the quotient of the coil flux, $\mathrm{N}$, due to the coil's own magnetic field divided by the current I in the coil." This is the way in which the coefficient is usually defined, but it is an exceedingly unsatisfactory way, for unless the conductivity of the wire be infinite, lines of magnetic induction penetrate the wire, and then it becomes difficult to understand what is meant by the "coil flux." It is impossible to escape from the difficulty by supposing the wire to become infinitely thin, for the only result of this is to make $L$ become infinite.

Later in the chapter the coefficient of self induction is defined by means of the expression $\left(\frac{1}{2} L I^{2}\right)$ for the energy of the system. It would be preferable to follow 
Maxwell and to adopt this definition at the outset, for it is from the value of the energy that the coefficient is always calculated.

The methods of vector analysis are so useful in electromagnetic theory and present so little difficulty that the reader naturally expects to find them used in a book which is intended to present a "thoroughly modern introduction" to that theory. The author makes a slight use of this analysis in his later chapters, but in the case of vector products adopts a hybrid notation. In the true vector analysis, as used by Heaviside, if the vector product of the two vectors $\mathbf{A}$ and $\mathbf{B}$, which make an angle $\theta$ with each other, be the vector $\mathbf{c}$, the result is denoted by

$$
\mathbf{c}=\mathrm{VAB} \text {, }
$$

while the magnitude (C) of the product is given by $C=A B \sin \theta$.

In the author's notation the relation between $\mathbf{c}, \mathbf{A}$ and $\mathbf{B}$ is expressed by

$$
\mathrm{C}=\mathrm{v} \mathrm{AB} \sin \theta \text {, }
$$

the letter $\mathbf{v}$ serving to indicate that $\mathbf{c}$ is at right angles to the plane of $\mathbf{A}$ and $\mathbf{B}$. It is difficult to see that this hybrid notation has any advantage over Heaviside's.

A few misprints have been noticed in a list sent out by the author; only a few others have been detected.

The reader has probably already gathered from this review that the treatise can hardly be described as that "good text-book" for which the student searches. Yet it is undoubtedly a useful book, and with a little modification and revision would be one of the best books of its class. The student who is fortunate enough to have it at hand will often turn to it with profit.

G. F. C. Searle.

\section{ASTRONOMICAL LECTURES AT CHICAGO.}

Astronomical Discovery. By Herbert Hall Turner, D.Sc., F.R.S., Savilian Professor of Astronomy in the University of Oxford. Pp. xi+225. With plates. (London: Fdward Arnold, 1904.) Price Ios. $6 d$. net

THE object of this book and the reason for its appearance are explained in a short preface. The purpose is "to illustrate by the study of a few examples, chosen almost at random, the variety in character of astronomical discoveries." The words "almost at random" seem a little out of place, for we learn that the book comprises the matter that was originally delivered in a series of lectures to the University students of Chicago, at the hospitable invitation of President Harper. The expression is probably not to be taken too seriously. It is not likely that a distinguished astronomer, enjoying what may be regarded as a cathedral position, would be careless in the preparation of his material. He would be anxious to give his best, both for the credit of English astronomy and for his own reputation. There is ample internal evidence, not only that the lectures were carefully prepared, but also of judicious selection.

NO. I 844 , VOL. 7 I]
The subjects chosen are about equally distributed between those that are made at the telescope and those that have resulted from the discussion of the observations so made. This will be seen from a list of the several chapters or lectures-(I) Uranus and Eros, (2) discovery of Neptune, (3) Bradley's discoveries of aberration and nutation, (4) accidental discoveries, (5) the sun-spot period, and (6) the variation of latitude. Some subjects which might have been expected to find a place, such as the discoveries resulting from the application of the spectroscope, have been omitted, but the list is sufficiently varied, and we gratefully acknowledge having received a considerable amount of pleasure from reading the well-known and familiar tales, treated, as they are, with the brightness and acuteness characteristic of the author.

The choice of the discovery of Uranus permits a well-deserved tribute to be paid to the memory of the elder Herschel for the keenness, assiduity and patience which mark the work of that astronomer; while the mention of Eros allows something to be said of the problem of the sun's distance and of the history of those times when the discovery of a small planet added something to the reputation of the lucky discoverer. The Savilian professor has some amusing remarks on the subject of naming the host of small planets that diligence has added to our catalogues. He quotes the case of Victoria as griving rise to an outcry by foreign astronomers, who objected to the name of a reigning sovereign being found in the list. But the real struggle of the purists was, we believe, over the christening of Fortuna; which Airy happily settled in favour of the discoverer's choice, by aptly quoting the well known lines of Juvenal :-

\section{"Nullum numen habes si sit prudentia}

Sed nos te facimus fortuna deam, cæloque locamus."

The second chapter or lecture is probably the least satisfactory in the book. The tale might have been told without parading the old scandal of sixty years ago to such wearisome length. Controversy seems out of place in lectures of this character. Prof. Turner in reopening the old sore has apparently two objects, the one, the whitewashing of Airy, and the other, the besmirching of Challis' reputation. Very hard things are said of the latter to which we do not wish to give further currency by repeating, but on the subject of Challis' lectures we doubt whether the words given in Airy's "Life" will bear the construction put upon them by Prof. Turner. There is no evidence to show, or at least the author has not produced it, that Airy's opinion was different in 1844 from what it was in 1834 , when he wrote to the Rev. T. J. Hussey: "I am sure it could not be done (predict the place of the disturbing planet) till the nature of the irregularity was well determined from several successive revolutions" (of Uranus), p. 43. Airy, it may be suggested, did not believe the problem soluble until he received Le Verrier's memoir in 1846 .

The account of Bradley's discoveries is excellent, and the feature in it which will be especially valued is the brief history given of the Rev. James Pound, 